\title{
Akute Sarkoidose
}

\section{Erster Hinweis am Sprunggelenk}

\section{Ein 33-jähriger Patient hat seit zwei Wochen Schmerzen im linken oberen Sprunggelenk (OSG), die plötzlich und ohne Trauma aufge- treten sind. Die Röntgenaufnahme des Thorax führt zur Diagnose.}

- Neben der Schwellung des OSG fällt eine druckdolente Rötung am lateralen Unterschenkel auf. Auch das linke Knieund Ellenbogengelenk sind schmerzhaft und morgensteif. Der hochgradige V. a. ein Löfgren-Syndrom lässt sich durch eine Röntgenaufnahme des Thorax bestätigen. Hier zeigt sich eine bihiläre Lymphadenopathie, die neben der Arthritis und dem Erythema nodosum Teil der typischen Löfgren-Trias ist.

Diese akute Sonderform der Sarkoidose betrifft vor allem Frauen im dritten Lebensjahrzehnt. Mit der Rückbildung der Symptome in vier bis sechs Wochen bei ca. 90\% aller Betroffenen ist der Verlauf günstig. Therapie der ersten Wahl sind

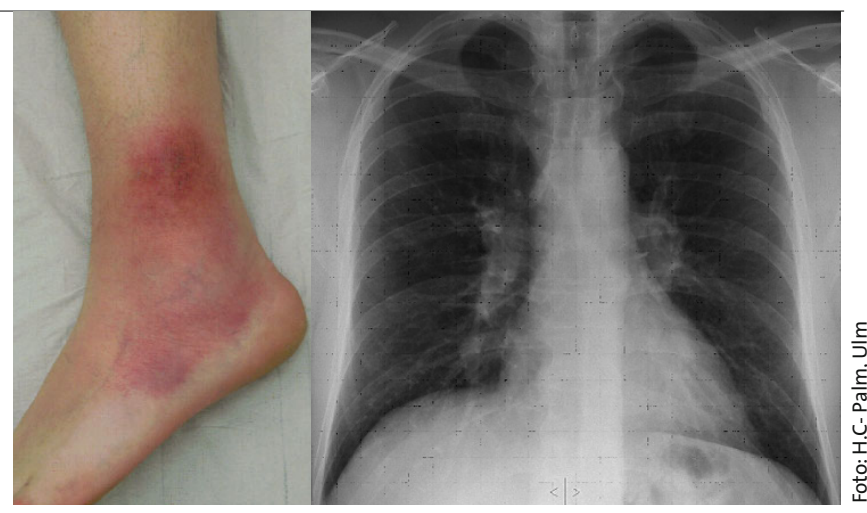

nicht steroidale Antiphlogistika, und nur bei hochakuter Arthritis sind Kortikosteroide indiziert.

Dr. med. H.-G. Palm, Dr. med. M. Helm, Priv.-Doz. Dr. med. B. Friemert, Bundeswehrkrankenhaus UIm 